Borneo Journal of Sciences and Technology, Volume (1), Issue (1), Pages: 33-35

DOI: https://doi.org/10.35370/bjost.2019.1.1-07

e-ISSN: 2672-7439

(C) 2018, UCTS Publisher.

Submitted: 31 October 2018

Accepted: 10 November 2018

Published: 31 January 2019

\title{
Modified Osgood Equation for Acacia Mangium
}

\author{
William L. N. Buglie and Mohd Shahril bin Osman \\ School of Engineering and Technology, University College of Technology Sarawak, \\ 868 Persiaran Brooke, 96000 Sibu, Sarawak, Malaysia
}

\begin{abstract}
The purpose of this study is to identify the Osgood's coefficient of species and the Modified Osgood Equation for Acacia mangium. Acacia mangium trees were cut to produce oven-dried Small Clear Specimens that were then tested until fracture. Results were gathered from static tensile tests in the direction parallel $\left(0^{\circ}\right.$ angle), perpendicular $\left(90^{\circ}\right.$ angle) and at $30^{\circ}$ angle to the wood grain. All test results confirmed that the Acacia mangium wood is brittle as there was no obvious necking observed on the test specimens. From the static testing, the Osgood's coefficient of species for Acacia mangium, $(a)$, is identified algebraically to be 0.49 . Acacia mangium, by nature, has a significant difference in the strengths parallel and perpendicular to the grain line. The finalized results of the Ultimate Tensile Strength for 15-year old Acacia mangium demonstrated that the Ultimate Tensile Strength in parallel and perpendicular to the grain directions are 143.87 MPa and 6.32 MPa respectively, while the Ultimate Tensile Strength at $30^{\circ}$ grain angle is $32.985 \mathrm{MPa}$. An extreme reduction of $95.6 \%$ of the Ultimate Tensile Strength was identified between $0^{\circ}$ and $90^{\circ}$ grain angles with a decreased value from 143.87 $\mathrm{MPa}$ to $6.32 \mathrm{MPa}$.
\end{abstract}

Keywords: Osgood, equation, Acacia, Mangium, coefficient.

\section{INTRODUCTION}

The Army Department of the United States of America developed the Hankinson's Equation/Criterion in 1921, which was intended for calculating the allowable compression stress of spruce wood at differing angles from the grain [1 and 3]. The finalized form of the equation was as Equation 1.

$$
S_{\theta}=\frac{S_{=} \cdot S_{\perp}}{S_{\bar{\nu}} \cdot \sin ^{2} \theta+S_{\perp} \cdot \cos ^{2} \theta}
$$

With,

$S_{\theta}=$ Ultimate Compression Strength at angle, $\theta$ to the grain.

$S_{\perp}=$ Ultimate Compression Strength perpendicular to the grain or at $0^{\circ}$ grain angle, $\mathrm{MPa}$.

$S_{=}=$Ultimate Compression Strength parallel to the grain or at $90^{\circ}$ grain angle, $\mathrm{MPa}$.

$\theta=$ Angle to grain line.

The Hankinson's Equation has also been generally accepted as a base formula in the Australia's ANSI/AF\&PA - National Design Specification for Wood Construction (NDS-2005) [4].
In 1928, Osgood, an Assistant Professor of Structural Engineering at Cornell University, publicized the Osgood Equation. It was a generalized version of the Hankinson Equation. The Osgood Equation is in the form of Equation 2.

$$
S_{\theta}=\frac{S_{s} \cdot S_{\perp}}{S_{\perp}+\left(S_{s}-S_{\perp}\right)\left(\sin ^{2} \theta+a \cdot \cos ^{2} \theta\right) \cdot \sin ^{2} \theta}
$$

With,

$a=$ coefficient of species, by which Osgood finalized the value for the Southern Yellow Pine wood as 0.35. $S_{\theta}, S_{\perp}, S_{=}$and $\theta$ are of the same as in the Hankinson's Equation.

Once the Osgood's coefficient, $(a)$ is increased to one (1), the Osgood Equation became the Hankinson's Equation. Hankinson's Equation is well-known for predicting the compression strength of wood at different angles to the grain line. Tests were conducted in order to review the application capability of the Hankinson's Equation for predicting the wood tensile strength according to the angles from the grain line. A tensile stress at a rate of 0.1 inches per minute was applied at varying angles from the grain of the Southern Yellow Pine board wood specimens. The study revealed that the

\footnotetext{
Corresponding Author: William L. N. Buglie. University College of Technology Sarawak, Tel: 084-367300, Fax: 084-367301, buglie@ucts.edu.my
} 
Osgood Equation was a better fit compared to the Hankinson's Equation for tensile loading [3].

\section{MATERIALS AND METHODS}

The experiment was mainly related to the static tensile testing of oven-dried tensile specimens (dog-bone shaped) at $0^{\circ}, 30^{\circ}$ and $90^{\circ}$ angles to the grain line. The test specimens were prepared according to the British Standard 373. Figure 1 shows the actual processed dog bone shaped tensile test specimens. All tests commenced at relative humidity $(\mathrm{RH})$ of $(65 \pm 2) \%$. The test specimens were produced from selected Acacia mangium trees that are 15 years of age. The static tensile test used a total of ninety (90) pieces of oven-dried Small Clear Specimen. As the specimens were tested at three (3) grain angle orientations, namely at $0^{\circ}, 30^{\circ}$ and $90^{\circ}$ angles, each orientation used a total of thirty (30) pieces of specimens. Tensile forces were applied at both ends of the specimen at a constant speed until failure occurred at the smallest cross section (slender part) of the specimen. Failure occurred in the form of rupture after 1.5 to 2 minutes after loading started.

\section{RESULTS AND DISCUSSION}

All test results confirmed that the Acacia mangium wood is brittle as there was no obvious necking observed on the test specimens. Results also showed the values of the Ultimate Tensile Strength at $30^{\circ}$ grain angle $\left(S_{30^{\circ}}\right)$ and $90^{\circ}$ grain angle $\left(S_{\perp}\right)$ are $32.985 \mathrm{MPa}$ and $6.32 \mathrm{MPa}$ respectively. Meanwhile, the value of the Ultimate Tensile Strength parallel to the grain line $\left(0^{\circ}\right.$ grain angle), $S_{\Rightarrow}$ is identified as $143.87 \mathrm{MPa}$. These values were then inserted into the Osgood Equation in order to determine the value of species coefficient, $(a)$, algebraically from the equation.

\section{Modified Osgood Equation for Acacia Mangium}

Osgood Equation (Equation 2) is in the form of:

$$
S_{\theta}=\frac{S_{\bar{\nu}} \cdot S_{\perp}}{S_{\perp}+\left(S_{\bar{\nu}}-S_{\perp}\right)\left(\sin ^{2} \theta+a \cdot \cos ^{2} \theta\right) \cdot \sin ^{2} \theta}
$$

By inserting the values of $S_{30^{\circ}}, S_{\perp}$ and $S$, the Osgood Equation becomes:

$$
32.947=\frac{143.87 \times 6.32}{6.32+(143.87-6.32)\left(\sin ^{2} 30^{\circ}+a \cdot \cos ^{2} 30^{\circ}\right) \cdot \sin ^{2} 30^{\circ}}
$$

Using the algebraic method, it was found that the coefficient of species, $a$, is equal to 0.49 .

As the final step, the finalized form of the Modified Osgood Equation for the Acacia Mangium was generated. This was done by substituting the values of $S_{30^{\circ}}, S_{\perp}, S=$, and $a$, into the Osgood Equation:

$$
\begin{gathered}
S_{\theta}=\frac{S=\cdot S_{\perp}}{S_{\perp}+\left(S=-S_{\perp}\right)\left(\sin ^{2} \theta+0.49 \cdot \cos ^{2} \theta\right) \cdot \sin ^{2} \theta} \\
S_{\theta}=\frac{143.87 \times 6.32}{6.32+(143.87-6.32)\left(\sin ^{2} \theta+0.49 \cdot \cos ^{2} \theta\right) \cdot \sin ^{2} \theta} \\
S_{\theta}=\frac{909.258}{6.32+(137.55)\left(\sin ^{2} \theta+0.49 \cdot \cos ^{2} \theta\right) \cdot \sin ^{2} \theta}
\end{gathered}
$$

Hence, the Modified Osgood Equation for Acacia Mangium that is 15 year of age is shown as Equation 3 below.

$$
\begin{aligned}
& S_{\theta} \\
& =\frac{909.258}{6.32+(137.55)\left(\sin ^{4} \theta+0.49 \cdot \sin ^{2} \theta \cdot \cos ^{2} \theta\right)}
\end{aligned}
$$

The simulated result of the Modified Osgood Equation for Acacia Mangium generates a curve that explains the relationship between tensile strengths and grain angles. This relationship is shown in Figure 2.

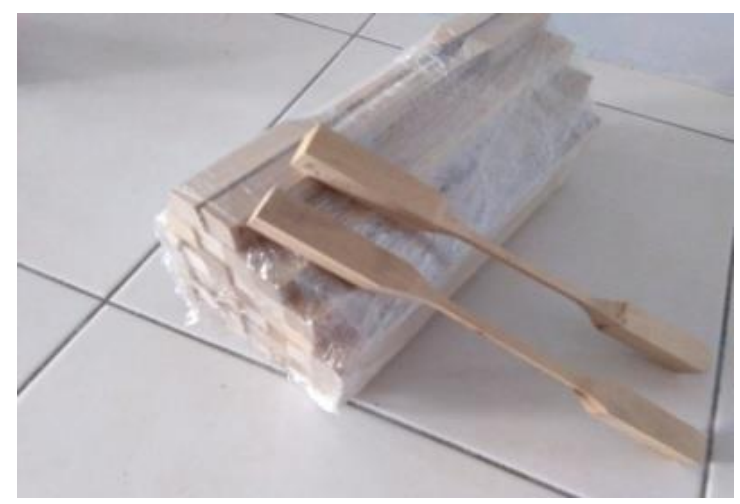

Figure 1: Dog bone shaped tensile test specimens 
Modified Osgood Equation for Acacia Mangium

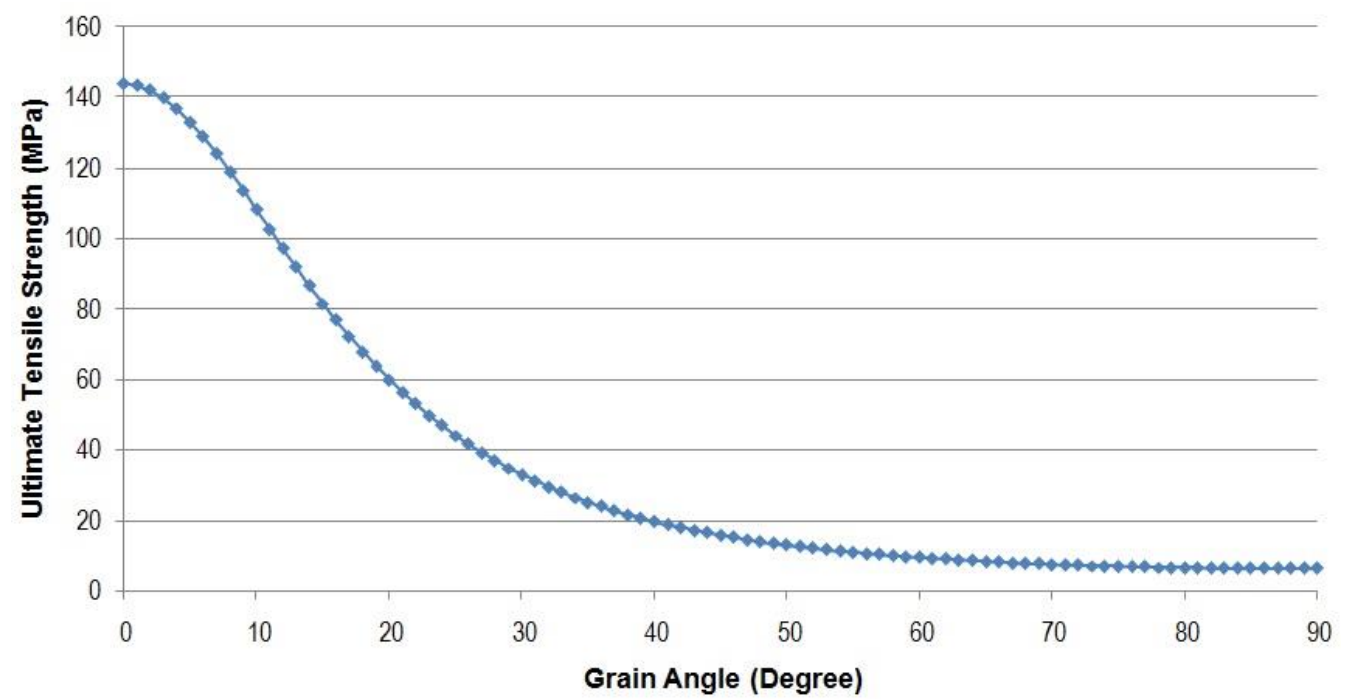

Figure 2: Ultimate Tensile Strengths based on Grain Angles (Simulation of the Osgood Equation)

\section{CONCLUSION}

All test results confirmed that the Acacia mangium wood is brittle, as no obvious necking was observed on all test specimens. From the static testing, the Osgood's coefficient of species for Acacia mangium, (a), was derived algebraically to be 0.49 . By nature, the Acacia mangium has significant difference in the strengths parallel and perpendicular to the grain line. The finalized results of the Ultimate Tensile Strength for a 15-year old Acacia mangium demonstrated that the Ultimate Tensile Strength in parallel and perpendicular to the grain directions as $143.87 \mathrm{MPa}$ and $6.32 \mathrm{MPa}$ respectively. Meanwhile, at $30^{\circ}$ grain angle, the Ultimate Tensile Strength is $32.985 \mathrm{MPa}$. An extreme reduction of $95.6 \%$ of the Ultimate Tensile Strength was identified between the $0^{\circ}$ and the $90^{\circ}$ grain angles where the value reduced from 143.87 MPa to 6.32 MPa. The Osgood Equation may be used to derive the Acacia mangium ultimate tensile strengths for grain angle domain of:

$$
0^{\circ} \leq \text { Grain angle } \leq 90^{\circ}
$$

\section{ACKNOWLEDGMENT}

The authors sincerely acknowledge and appreciate the University College of Technology Sarawak (UCTS) and Sarawak Forestry Corporation (SFC) for the support throughout the whole research process.

\section{REFERENCES}

[1] Bodig, J. and Jayne, B. A. (1982). Mechanics of wood and wood composites $1^{\text {st }}$ edition. Florida: Krieger Publishing Company.

[2] British Standard. (1957 confirmed 2008). Method of testing small clear specimens of timber, BS 373. London: British Standard.

[3] Kim, K. Y. (1985). A note on the Hankinson Formula. Wood and Fiber Science V, 18 (2).

[4] Suryoatmono, B. and Pranata, Y. A. (2012). An alternative to Hankinson's Formula for uniaxial tension at an angle to the grain. In: World Conference on Timber Engineering 2012, 16 - 19 July 2012, Auckland. 